\title{
The Implementation of Artificial Intelligence in Geometry Validation for Psychomotor Aspect Assessment
}

\author{
Siska Arifiani*, Umi Laili Yuhana, Ridho Rahman Hariadi, Faturochman Pranacahya Andrianto \\ Department of Informatics \\ Institut Teknologi Sepuluh Nopember \\ Surabaya, Indonesia \\ *siska@its.ac.id
}

\begin{abstract}
Nowadays, many various of geometry validation tools produced to validate the shapes drawn automatically. The tools are useful to create geometry shape, for example: vertices, edges, and faces. This paper proposed a technique in geometry validation using an artificial intelligence (AI). The proposed method is to develop a 3D virtual environment for VR application. To support these circumstances, we use Oculust Rift and leap motion control. First, user will create random shapes in a system and the system do the validation. Second, after the validation, the system will show a correct information if the shape is correct. However, the system will show an incorrect information, if the shape is incorrect. Each point of shape that drawn will be marked and will be checked by the system. Last, Leap Motion Controller will match the hand gesture and the shape result. A virtual world will be show in Oculus Rift. This is necessary for the user in order to create a real feeling in the virtual world and do the interaction using leap motion control. This research aims also to do an evaluation of psychomotor aspect for the user. Several students in elementary school already tested and have a high interest, since the application is very useful and interactive.
\end{abstract}

Keywords—artificial intelligence, psychomotor, Assessment

\section{INTRODUCTION}

Children's behaviour depends on how we educate and caring them. The positive strategies are needed to be developed to build children's behaviour. The behaviour guidance is used to develop current thinking about the most positive and effective ways that can help children's understanding and learning skills. This will help them to manage their own behaviour. To educate children, we are not permitted to do the corporal punishment and unreasonable discipline. Not only because children may be physically harmed, but also it will cause detrimental effects on the children.

Children like playing. To develop their behaviour many approaches developed and one of those approaches is innovative learning media by using game. The active children cannot be quite all the time. They will do whatever they want.
And our treatments will affect to the children's behaviour. False treatment can lead into a bad behaviour.

The interactive media learning now days uses many technologies such as Virtual Reality (VR) and Augmented Reality (AR). This research use VR to develop more immersive and interactive learning media. This application can help to track and do some exercise anywhere and anytime. This research does not only try to help children in learning, but also to help children to improve their psychomotor aspect. The psychomotor aspect is important, it is explained by Indonesian Ministry of Education and Culture (Permendikbud No.24 2016) that students need to have three aspects which is cognitive, affective, and psychomotor [1]. These three aspects are the standard measurement to evaluate student valuation. Cognitive is used to evaluate the capability of student in apprehend the lessons. Affective is used to evaluate the respond what the student gives while accepting the lesson. Psychomotor is used to evaluate all the lesson student have by implementing it. Psychomotor aspect has an importance role to evaluate all the lesson because it is the last point student should achieve.

Psychomotor aspect to evaluate someone physics abilities about coordination, formation, and verbal and nonverbal processing [2]. It's all about motor activity which conducted to several solve problems. One of the latest technologies that use almost all of human body to interact with digital environment is virtual reality [3]. This technology makes user feels like inside the virtual world. Virtual reality is a suitable method to evaluate psychomotor aspect since the users should use almost part of their body to interact with the system [3]. Virtual reality is used by some of the commercial corporation such as Oculus Rift and Leap Motion. Oculus Rift is a technology that manipulate vision and audio of the user [4]. It causes user to feel the sensation for living in the digital world. Leap Motion is a technology with the intention of control the application using full control of the user hands. It can grab, pinch, push, and many interactions that can implemented like in real world.

This research provides psychomotor evaluation using Oculus Rift and Leap Motion to develop an interactive learning 
media. The Leap Motion Controller is used to interact with 3D virtual object by using the hand motion. The target user of this application is students in Elementary school. The application developed helps student to improve their psychomotor by writing and drawing. To minimize error and fault in writing and drawing, this research proposes Smoothing Via Iterative Averaging (SIA) algorithm [5]. SIA is used to make the line drawn by user smoother. In this research, standard deviation and linear equation are also used to help the geometry validation. This research is expected to be able to help in psychomotor aspect assessment for student in elementary school.

\section{PROPOSED SYSTEM}

\section{A. Psychomotor Aspect}

In 1950 there was a team consists of psychology expert that led by Benjamin Bloom that purpose of this team to analyse behaviour while studying [1]. From this research it produces methods that used to measure student competence that called Bloom's Taxonomy. This is the three aspects that have been explained by Indonesian ministry of Education and Culture that every lesson should observe cognitive, affective, and psychomotor.

Psychomotor aspect is used to apply all the experience and knowledge that a person has. For example, such as:

- Practical exam about chemistry

- Performing arts

- Swimming practice

A person has a good psychomotor aspect if they can do all the activity quick, accurate, smooth, and robust. They cannot do better if they do not know the basic of the activity, they do by means is the theory which obtained by the cognitive and affective of a person. The aspect of psychomotor can be listed as follow.

- Action

- Coordination

- Formation

- Production

The psychomotor aspect to evaluate someone physics abilities about coordination, formation, and verbal and nonverbal processing [2]. It's all about motor activity which conducted to several solve problems. The psychomotor aspect observes the accuracy, neatness, speed, and strength in solving the problem. In this research, the psychomotor aspect that will be measured is the ability to write and draw correct line based on the question shown. The application will show question about geometry to be solved by students in elementary school. The question is about 2D/3D shapes, symmetry, area and circumference of a shape.

\section{B. System Design}

This application constructed by Unity 3D SDK version 2018.3.6f and using $\mathrm{C \#}$ as the programming language. For the usage of the Leap Motion can be download in Leap Motion official website. The application starts from registration view for user and end at the exit button. User only use Leap Motion as the controller and Oculus Rift as the display of this application.

The architecture of the application developed is shown in Figure 1. The main purpose of this architecture is to integrate between Oculus Rift and Leap Motion. Computer is used to process all the input and output from the system by integrating the Leap Motion device and Oculus Rift. All the scene and environment are displayed by the Oculus Rift. The Oculus Rift include the head mounted display. This device can be used to show the virtual environment. Leap Motion is used to navigate user inside the application by using hand motion and gestures. Leap Motion is a small device that is built with optical sensors and infrared light which allows the system to recognize and track hands, fingers and small tools [6]. Leap Motion can track multiple entities in order to function according to its procedures. The objects known to Leap Motion use the object frame type. Each frame object consists of several lists of detected frame entities such as hands, fingers, and small tools.

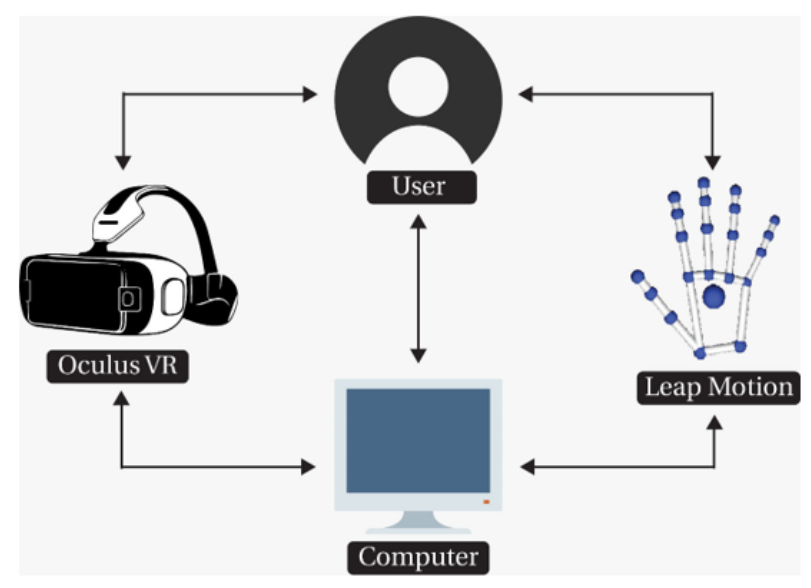

Fig. 1. The architecture of application developed

The hand is the main entity that will be tracked by Leap Motion which is included in the hand class. From this class, you can access some other information such as the position of the hands, arms, and fingers. Leap Motion provides information for each finger on the hand such as position, direction, and finger bones. This information is contained in the fingers class which consists of several names such as thumb, index, middle, ring, and pinky. Apart from being able to detect hands and arms, Leap Motion can detect small, relatively cylindrical tools such as a pencil. Tools are represented in the Tools class which provide information such as position and direction.

Unity 3D is used to build the virtual environment and integrate the devices. The user will draw the shape shown in 
the question, and the system will validate the result. To smooth the line drawn by user, this application use SIA algorithm. And to validate the shape drawn by user, this research used standard deviation and linear equation. If user can draw the shape correctly, the system will show correct label. And if the user can not draw the shape correctly, the system will show label that the answer is incorrect.

1) SIA (Smoothing Via Iterative Averaging): Line smoothing is unlike simplification that reduce the detail. Line smoothing is to shift the position of points to make a line. In the process of line smoothing, the perturbations will be removed, and it will be captured only the most significant trends of point in the line. There are several line smoothing algorithms i.e. averaging, convolution, and neighbouring points. This research uses SIA (Smoothing via Iterative Averaging). The basic concept of this algorithm is to find the median of the neighbours of each point. The result of the median of each point creates the new coordinates for the original point. The input of this algorithm is explained as follows.

a) Line: The first input in this method is line as object. Line object is a list of points or vertices. In this algorithm, it is assumed that the list of points is sorted.

b) Smoothing Sensitivity (SS): $\mathrm{SS}$ indicates the two neighbours of the coordinates you want to smooth. Distortion occurs when the SS value set becomes higher.

c) Smoothing Iterative (SI): SI is the important parameter in this smoothing process. In SIA, SI is used to generate the most optimal line in some process iteration.

d) Smoothing Preservation (SP): $\mathrm{SP}$ is a variable that is used to keep the originality of the line, without reducing the smoothness of the lines.

There are many approaches in smoothing the line e.g. Walter [7], Greenblatt [8], and Goliński and Przestacki [9]. This research uses SIA algorithm. There are many factors why SIA chosen e.g. this algorithm is easier to be implemented. Besides the computation of this algorithm is better than the others algorithm [10].

2) Standard deviation: Standard deviation is the statistic method used to determine how the data are distributed in a sample and how close the individual data points are to the mean, average, or sample value $[11,12]$. This method is used to measure the error rate of a population or data sample. The smaller the value of the standard deviation, the better the data or population sample obtained. The formula for the standard deviation of the total population can be seen in Equation 1.

$$
s^{2}=\frac{\sum_{i=1}^{n}\left(x_{i}-\bar{x}\right)^{2}}{n}
$$

This method can have used data samples. The formula for measuring the error rate of a sample of a population can be seen in Equation 2.

$$
s=\sqrt{\frac{\sum_{i=1}^{n}\left(x_{i}-\bar{x}\right)^{2}}{n-1}}
$$

From its definition, this method can be used to measure the error rate between the lines drawn and the straight lines drawn Population data is a sample of all points drawn by the user and the average value of the population can be obtained from a straight line created by the user. To find a straight line, you can use the formula to find the linear equation of two points. The formula that will be used to find a straight line can be seen in Equation 3.

$$
y=m x+c
$$

The linear equation formula is used to find a graph between two coordinates $[13,14]$. This equation is very useful to find the optimum straight-line of the drawn line to compared of the user has drawn. Formula to finding the linear equation can be seen on Equation 3 and 4. In Equation 4 is used for special case is when the $\mathrm{x}$ coordinate for the start and ending point are the same [6].

The formula used to find the slope of the linear equation can be seen in equations 4 .

$$
m=\frac{y 2-y 1}{x 2-x 1}
$$

If $\mathrm{x} 2-\mathrm{x} 1$ is 0 then the formula for finding a straight line can be seen in equation 5 .

$$
y=x 1
$$

\section{RESUltS AND DISCUSSION}

The application developed runs in PC with Oculus Rift and Leap Motion Controller installed. When the devices are ready to be used, the application can be run. There are two psychomotor assessments in the application i.e. 2-dimentional and 3-dimentional shape. The concept aims to evaluate the ability of student in geometry. The application will show a question to be solved by user. The problem can be image of 2dimentional or 3-dimentional shapes. User will analyse the image and draw the image in the white board provided by the application. There is a grid in the white board. So, user can draw the line easy. To assess the user's drawn, this application provides 0-100 for the score. The score is based on the standard deviation and linear equation result. The higher score is obtained when the object drawn by the user is more similar with the object in the question. Figure 2.a. shows the question that must be drawn by the user. Figure 2.b shows the user's finger that is drawing lines. The Figure 2.c. shows the shapes formed by the lines drawn by user. If the shapes drawn is not 
similar with the question, the application will show label that informs that the answer is not correct. When user draws incorrect answer, the application will not show the next question. The user must finish the question first, before they can continue for the next questions.

To test the reliability of the application, this research conducted the functional testing and user experience testing. The functional testing aims to test the functionality of the system to find error, bug, or fault. The user experience test was conducted to measure the user experience of the system. The system was tested to 14 students in Elementary school i.e. SD Muhammadiyah 26 Surabaya. The result shows that the system can help students to learn geometry. The main problem in the user experience testing is the installation process. Many devices used in this system, affect to the installation process. Besides, the devices are expensive to buy. It causes many schools refuse to use this system as an alternative media to learn geometry.

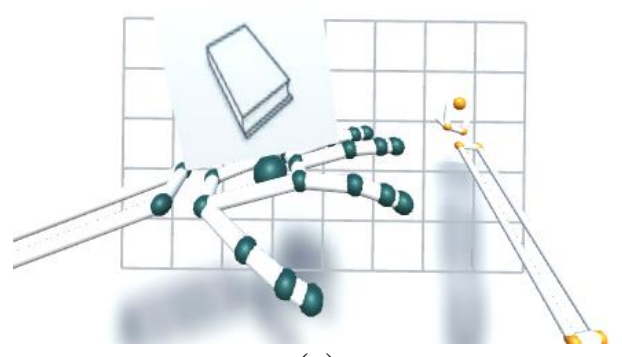

(a)

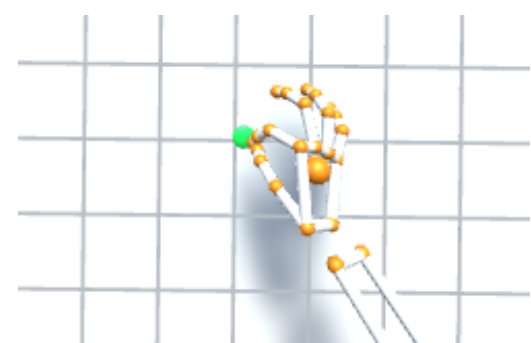

(b)

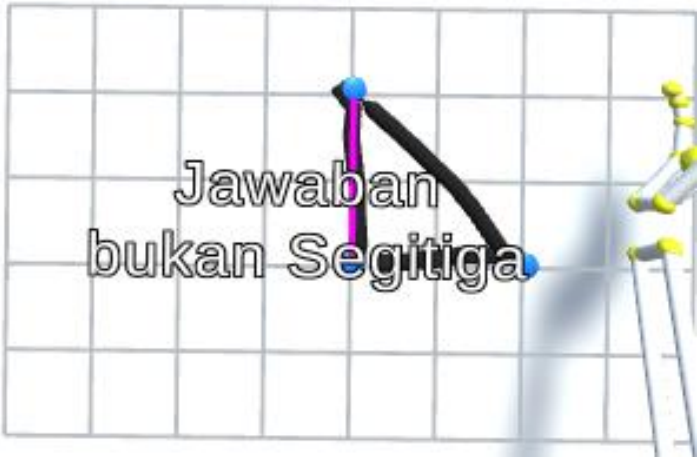

(c)

Fig. 2. The Steps of the system i.e. (a) The system shows the question, (b) The process in drawing line, (c) The result shows by the system when the user finish draws the lines.

\section{CONCLUSION AND FUTURE WORK}

The application developed is work well without any error, bug, or fault found. This application can recognize the hand motion and gestures. This application implements VR technology by using Oculus Rift and Leap Motion Controller. The Oculus Rift is used to show the virtual environment and the Leap Motion Controller is used to provide interaction between user and the virtual object. This research is expected to be able to help in psychomotor aspect assessment for student in elementary school. The psychomotor aspect that will be assessed is the ability of student in draw shape correctly. Some parameter that is used in this assessment i.e. accuracy, neatness, speed, and strength in solving the problem.

To smooth the line drawn in the application, this research uses SIA ((Smoothing Via Iterative Averaging) algorithm. To validate line and shape drawn, this research implements standard deviation and linear equation. Standard Deviation is used to measure the error rate between the lines drawn and the straight lines drawn, while the linear equation formula is used to find a graph between two coordinates. To assess the user's drawn, this application provides 0-100 for the score. The score is based on the standard deviation and linear equation result. The higher score is obtained when the object drawn by the user is more similar with the object in the question.

\section{REFERENCES}

[1] Menteri Pendidikan, "Peraturan Menteri Pendidikan dan Kebudayaan Republik Indonesia," Nomor, vol. 66, pp. 1-3, 2016.

[2] A. Nurwati, "Penilaian Ranah Psikomotorik Siswa dalam Pelajaran Bahasa," Edukasia J. Penelit. Pendidik. Islam, vol. 9, no. 2, 2014.

[3] E. Hu-Au and J.J. Lee, "Virtual reality in education: a tool for learning in the experience age," Int. J. Innov. Educ., vol. 4, no. 4, pp. 215-226, 2017.

[4] S. Katchhi and P. Sachdeva, "A Review Paper on Oculus Rift," Int. J. Curr. Eng. Technol. E-ISSN, pp. 2277-4106, 2014. 
[5] M. Mansouryar and A. Hedayati, "Smoothing via iterative averaging (sia) a basic technique for line smoothing," Int. J. Comput. Electr. Eng., vol. 4 , no. 3, p. 307, 2012.

[6] MathisFun, "MathisFun: Linear Equation," https://www.mathsisfun.com/algebra/linear-equations.html

[7] R. Walter, "A note on 'Workload smoothing in simple assembly line balancing," Comput. Oper. Res., vol. 113, p. 104803, 2020.

[8] M. Greenblatt, "Smooth and singular maximal averages over 2D hypersurfaces and associated Radon transforms," Adv. Math. (N. Y)., vol. 377, p. 107465, 2021.

[9] M. Goliński and A. Przestacki, "The invariant subspace problem for the space of smooth functions on the real line," J. Math. Anal. Appl., vol. 482, no. 2, p. 123565, 2020.

[10] P. Rosen and G.J. Quadri, "LineSmooth: An Analytical Framework for Evaluating the Effectiveness of Smoothing Techniques on Line Charts," IEEE Trans. Vis. Comput. Graph., 2020
[11] K. Wang, "Asynchronous standard deviation method for fault detection," in 2014 Prognostics and System Health Management Conference (PHM-2014 Hunan), 2014, pp. 233-236.

[12] V. Khieovongphachanh, S. Kanthavong, K. Hamamoto, and M Chanthavong, "Image quality criterion of ultrasonic echo image using Standard Deviation," in The 4th Joint International Conference on Information and Communication Technology, Electronic and Electrical Engineering (JICTEE), 2014, pp. 1-3.

[13] P. Dawkins, "Paul's Online Notes NOTES QUICK NAV DOWNLOAD," 2020 https://tutorial.math.lamar.edu/classes/alg/solvelineareqns.aspx\#: :text= A linear equation is any,start off in this form.

[14] Byjus, "The Learning App: Linear Equation." https://byjus.com/maths/linear-equations/. 